www.periodicos.unimontes.br/index.php/caminhosdahistoria

\title{
A DIMENSÃO ESPAÇO-TEMPORAL EM FERNAND BRAUDEL: UMA LEITURA DA REPRESENTAÇÃO DO TEMPO HISTÓRICO BRAUDELIANO E SEUS APORTES TEÓRICOS
}

\author{
Rodolpho Alexandre Santos Melo Bastos ${ }^{1}$
}

\begin{abstract}
Resumo: Este artigo investiga a representação do tempo histórico - a longa duração - do historiador francês Fernand Braudel a partir da comparação com a os estudos da antropologia estruturalista de Lévi-Strauss. Para isso, em um primeiro momento, iremos apontar as diferenças e semelhanças entre o pensamento de Braudel que parte da temporalidade longa como estrutura da sociedade, que é subsidiada pelas curtas e médias durações e a "intemporalidade" contida no pensamento estruturalista e Lévi-Strauss, que tende homogeneizar o tempo. Com isso, encontrar no tempo longo braudeliano à aplicabilidade na vida material das sociedades, como o cotidiano das pessoas, do capitalismo, cidades, economia, etc. Em um segundo momento, iremos apontar que mesmo essa concretude do pensamento temporal de Braudel em relação a Lévi-Strauss, será possível encontrar elementos de apontam para uma determinada corpo de axiomas e leis, ao propor o tempo longo como causa temporal que determina as outras temporalidades, através de elementos epistemológicos que remetem a um a priorismo, universalidade, imobilidade, entre outros.
\end{abstract}

Palavras-chave: Braudel; Longa Duração; Lévi-Strauss; Tempo Histórico; Filosofias da História.

Abstract: This paper investigates the representation of historical time - the long duration - of the French historian Fernand Braudel from the comparison with the studies of structuralist anthropology by Lévi-Strauss. For this, in a first moment, we will point out the differences and similarities between Braudel's thought that starts from long temporality as a structure of society, which is subsidized by short and medium durations and the "timelessness" contained in structuralist Lévi-Strauss thinking, which tends to homogenize time. With this, finding in Braudelian long time the applicability in the material life of societies, such as people's daily lives, capitalism, cities, economics, etc. In a second step, we will point out that even this concreteness of Braudel's temporal thinking in relation to Lévi-Strauss, it will be possible to find elements that point to a certain body of axioms and laws, by proposing long time as a temporal cause that determines the others temporalities, through epistemological elements that refer to a priority, universality, immobility, among others.

Keywords: Braudel; Long Duration; Lévi-Strauss; Historical Time; Philosophies of History.

Resumen: Este artículo investiga la representación del tiempo histórico, la larga duración, del historiador francés Fernand Braudel a partir de la comparación con los estudios de antropología estructuralista de Lévi-Strauss. Para esto, en un primer momento, señalaremos las diferencias y similitudes entre el pensamiento de Braudel que parte de la temporalidad larga como una estructura de la sociedad, que está subsidiada por duraciones cortas y medias

\footnotetext{
${ }^{1}$ Doutorando em História pelo Programa de Pós-graduação em História da Universidade Federal de Santa Catarina (UFSC), integrante do Núcleo Interdisciplinar de Estudos Medievais (Meridianum-UFSC), Grupo de Estudos entre o Feminino e o Masculino na Longa Duração (GEFEM-UFSC) e Bolsista CAPES. E-mail: rodoxbastos@gmail.com. ORCID iD: https://orcid.org/0000-0002-5167-0843
} 
y la "atemporalidad" contenida en el pensamiento estructuralista y Lévi-Strauss, que tiende a homogeneizar el tiempo. Con esto, encontrar en Braudelian mucho tiempo la aplicabilidad en la vida material de las sociedades, como la vida cotidiana de las personas, el capitalismo, las ciudades, la economía, etc. En un segundo paso, señalaremos que incluso esta concreción del pensamiento temporal de Braudel en relación con Lévi-Strauss, será posible encontrar elementos que apunten a un cierto cuerpo de axiomas y leyes, proponiendo un largo tiempo como causa temporal que determina a los demás temporalidades, a través de elementos epistemológicos que hacen referencia a una prioridad, universalidad, inmovilidad, entre otros. Palabras clave: Braudel; Larga duración; Lévi-Strauss; Tiempo histórico; Filosofías de la historia.

\section{Introdução}

Os projetos conhecidos como filosofia da história dos séculos XVIII e XIX, de acordo com Gardiner (2004), pretendem oferecer um panorama completo do processo histórico, no qual se pode vislumbrar um determinado sentido para a história. Entretanto, tais filosofias da história oferecem, ao mesmo tempo, um caráter obscuro, ao possibilitarem uma forma de conhecimento historiográfico inverificável, a-histórico, imutável e, por isso, não científico.

É neste contexto que no século XIX, segundo Reis (2006), é identificada uma tentativa de se produzir uma história científica, ao seguir pelo menos três direções principais: A orientação Diltheyana, que aspira encontrar algo específico no conhecimento histórico que a torna "ciência" distinta das ciências naturais; a Rankiana, que aproxima a história científica da física e a orientação Marxista que, ao partir da práxis submete o conhecimento históricocientífico a sua realidade histórica.

Apesar do esforço do conhecimento histórico em romper com a filosofia, ou melhor, com as filosofias da história, que por um lado obtiveram sucesso, por outro não conseguiram desvencilhar em relação às formulações universalizantes dos filósofos. A própria historiografia positivista do século XIX (e da primeira metade do XX), com suas pretensões de um conhecimento puro, sistematizados e verdadeiros, em que o trabalho do historiador seria apenas de dar voz as fontes, sendo dispensável suas interpretações, pode ser caracterizado dentro de um sistema teleológico, com leis gerais, universalizantes, com eventos únicos, irrepetíveis e singulares, além de prognóstica e/ou teleológica. Tais preceitos estão próximos de produção de uma metafísica e/ou doutrinas filosóficas com seus axiomáticas e leis causais, sendo mais uma das várias tipologias de filosofias da história.

Para Gardiner (2004), as filosofias da história possuem um caráter linear e progressivo, características certamente herdadas do Iluminismo, apresentando também uma a evolução das teorias das descontinuidades históricas e teleológicas. Tais filosofias operam 
como modos de percepções sobre processos históricos fundamentados em filosofias que pretendem modelar a história por meio de um sentido da trajetória da humanidade e o meio social que a circunda.

A própria Escola dos Annales do século XX, mesmo preocupadas em fugir das filosofias da história ao se aproximarem do método das Ciências Sociais, não puderam evitar certa dose de "metafísica" em algumas de suas representações de tempo, como longa duração de Braudel. Segundo Reis (2000, p.30), “a história estrutural” do século XX não está isenta de um desejo de "evasão" e procurará construir sua esperança utópica. Não buscará nem o instante eterno, a reversibilidade circular, a linha escatológica e nem utópica “[...] interrompida no início e no fim, no interior da qual há repetição, uma sucessão sem mudança ou com mudança reversível, que cria a confortável, aconchegante, sensação de identidade, de eternidade, de presença".

A "estrutura social" das ciências sociais e a "longa duração" dos Annales seriam a versão do século $\mathrm{XX}$ da reversibilidade, que protege contra o novo, a alteridade, a mudança, a finitude. Isso porque toda representação do tempo além de produzir meios de conhecer a história, para dominá-la, oferece também a representação do seu significado, da sua direção, do seu sentido, uma "utopia" (REIS, 2000, p.30).

Entendendo, desse modo, a longa duração como um "sistema de sistemas", uma estrutura suprema e que, segundo o próprio Braudel (1982, p.17), “[...] Equivale a familiarizar-se com um tempo que se tornou mais lento, por vezes, até quase ao limite da mobilidade [...] todos os milhares de fragmentação do tempo da história, se compreendem a partir desta profundidade, desta semi-imobilidade; tudo gravita em torno dela". O tempo longo se perde na dimensão da espacialidade, em que o espaço freia o tempo, sendo dimensão e temporalidade correspondentes, uma geografia espacial e dimensional - geo-história - a favor da história, da longevidade do tempo.

Com isso, o objetivo deste trabalho consiste em analisar o conceito de longa duração de Braudel em detrimento da noção de "intemporalidade" de Lévi-Strauss, para demonstrar como a curta e média ${ }^{2}$ duração do primeiro pode estar relacionada com o status de (quase) imobilidade. Deste modo, esses estratos temporais possibilitam a existência de aportes teóricos tradicionais à Filosofia, como as filosofias da história, como o devir, a imobilidade, universalidade e a priorismo, por exemplo.

Neste sentido, a imobilidade se disfarça de camadas de tempos que aparentemente se movimenta, mas que não transforma ou toca a estrutura, operando como uma forma de

\footnotetext{
${ }^{2}$ Sobre a curta e média duração, ainda faremos os devidos esclarecimentos no decorrer do artigo.
} 
conhecimento a priori, causal, atemporal e com pretensões universais. Por fim, analisaremos como a espacialidade, a geografia e a noção de longa dimensão de Braudel contribui para sua concepção de temporalidade longa, em que a dimensão espacial freia o tempo.

As fontes escolhidas para a realização deste artigo são os trabalhos de Fernand Braudel, especialmente aqueles que dizem sobre sua concepção de tempo histórico, como o seu famoso artigo A longa duração, publicado em 1958 e contido no livro História e Ciências Sociais, além de sua obra: Civilização Material, Economia e Capitalismo: Séculos XV-XVII. Outra fonte de grande relevância são os estudos de Lévi-Strauss sobre o estruturalismo, etnografia e história, como seu livro: Antropologia Estrutural. Este estudo permite perceber as principais questões sobre os debates pertinentes entre o campo das ciências sociais e a história, além das semelhanças e diferenças entre o estruturalismo de Lévi-Strauss e o tempo longo de Braudel.

\section{Lévi-Strauss e Braudel: um embate teórico sobre o tempo}

Para prosseguirmos com o desenvolvimento deste artigo é necessário recorrermos ao pensamento estruturalista de Lévi-Strauss e sua relação, seja em divergência ou convergência, com a longa duração de Braudel para localizarmos indicativos da presença de determinados elementos referentes a aportes teóricos de um conhecimento filosófico ou metafísico, como acontece nas filosofias da história.

Lévi-Strauss (1975, p.13), em defesa do renascimento da etnologia e etnografia, coloca em dúvida os saberes da sociologia e as pretensões de cientificidade da história. "É forçoso constatar que a História se ateve ao programa modesto e lúcido que se tinha proposto e que prosperou segundo suas linhas [...]". Ele formula questionamentos que os historiadores não se propunham, ou questões a partir de outra perspectiva. Dentro de um viés de distanciamento, o autor irá suscitar no seio da história uma série de mal-entendidos e resistências, ao mesmo tempo em que convida os historiadores se deslocarem seu ponto vista sobre seu próprio objeto.

Ainda de acordo com Lévi-Strauss (1975, p.4),

[...] a etnografia e a etnologia desabrocharam no curso dos últimos trinta anos, numa prodigiosa floração de estudos teóricos e descritivos, mas a custa de conflitos, discórdias e confusões onde se reconhece transposto ao próprio seio da etnologia o debate tradicional que parecia opor a etnologia em seu conjunto a uma outra disciplina, a história, igualmente considerada em seu conjunto. 
Para Hartog (2006, p.10), “[...] os debates e os combates focalizaram-se, principalmente, sobre a noção de estrutura, sustentada pela autoridade linguística". Segundo o próprio Lévi-Strauss (2008, p.45), no "conjunto das ciências sociais ao qual pertence indiscutivelmente, a linguística ocupa, [...] lugar excepcional: ela não é uma ciência social como as outras, [...] a única, sem dúvida, que pode reivindicar o nome de ciência".

O estruturalismo de Lévi-Strauss se pauta em um inventário de possibilidades inconscientes ao retomar a fórmula de Marx de que os homens fazem sua própria história, mesmo sem saber que a fazem, pois enquanto o historiador vai do explícito ao implícito, o etnólogo vai do particular ao universal. Deste modo, o que distingue a história da etnologia não é nem o objeto e nem o objetivo e sim a escolha de perspectivas complementares.

[...] tendo o mesmo objeto, que é a vida social; o mesmo objetivo, que é uma compreensão melhor do homem; e um método que varia apenas na dosagem dos processos de pesquisa, elas se distinguem sobretudo pela escolha de perspectivas complementares: a história organizando seus dados em relação às expressões conscientes, a etnologia em relação às condições inconscientes da vida social (LÉVI-STRAUSS, 2003, p. 33-34).

Nota-se que Lévi-Strauss, nessa passagem, está se referindo a história de historiadores positivistas e não os adeptos da Escola dos Annales. De toda forma, Hartog (2006, p.13) diz que Lévi-Strauss fornece uma arquitetura lógica aos desenvolvimentos da história que podem ser imprevisíveis, sem serem arbitrários, ao mesmo tempo em que o antropólogo acrescenta que "[...] o historiador socorre-se de todo o aparelho das elaborações inconscientes (é aqui que aparece o exemplo de Rabelais)". Para Reis (2008, p.13),

Lévi-Strauss acredita na perenidade da natureza humana, que se revela na ordem mental, intelectual. $O$ intelecto humano é permanente e se impõe sobre a mudança. Para ele, o social não predomina sobre o lógico-intelectual. As estruturas lógicas das normas e costumes abolem a mudança histórica. A busca da inteligibilidade não chega à história: parte dela, para aboli-la. O espírito humano é sempre idêntico a si mesmo e predomina sobre o social e o histórico. A história não diferencia o "selvagem" e o "civilizado", pois têm a mesma estrutura lógico-intelectual, que torna irrelevante a sua aparente diferença histórica. Lévi-Strauss prefere distinguir as sociedades "arcaicas" das "históricas" pela relação que mantêm com a temporalidade. [...] Para ele todas as sociedades são históricas. Entretanto, algumas o admitem francamente, enquanto por outras a historicidade é rejeitada e ignorada. As sociedades mitológicas negam a história [...] A mitologia resiste a mudança histórica ao reequilibrar o sistema.

Ainda conforme Reis (2008), a etnologia de Lévi-Strauss é oposta a história em três aspectos: institucionalmente, quando as ciências sociais tentam controlar as instituições de ensino e pesquisa; epistemologicamente, quando se opõe a história progressiva, evolutiva, teleológica, ideológica e não científica e apresentam uma análise matemática e científica; 
politicamente, contrapondo o projeto utópico-revolucionário da modernidade, dissolvendo sua ordem natural sagrada, através da desaceleração conservadora da história.

Braudel formula seu conceito de representação do tempo histórico como resposta as investidas de Lévi-Strauss. A longa duração surge como a representação de tempo formalizado por Braudel, que tinha por preocupação e problema, resolver e demonstrar como o tempo avança em diferentes velocidades. Foi esta preocupação que o levou a escrever um famoso artigo intitulado: A longa duração, publicado em 1958 que, segundo Cardoso e Vainfas (1997) formulou com nitidez a sua teoria sobre os tempos da história, aprofundando-o principalmente sobre o desenvolvimento do tempo longo, sendo o tempo das estruturas e quase imóvel, tempo da relação entre o homem e a natureza".

O tempo longo enfatiza a continuidade e a estrutura, tendo em vista que as permanências e a mudança lenta dão sentido à história e aos seus eventos, nos quais todas as suas camadas temporais (curta, média e longa) se medem por uma mesma escala, em que está inserido em algum desses tempos, é participar de todos eles. Pois, o tempo histórico segundo Braudel (1983, p.12)

[...] divide-se em três partes, [...] A primeira trata de uma história, quase imóvel, que é a do homem nas suas relações com o meio que o rodeia, uma história lenta, de lentas transformações, [...] quase sempre fora do tempo. [...] Acima desta história imóvel, [...] distinguir-se uma outra, caracterizada por um ritmo lento: [...] a história dos grupos e agrupamentos [...], as economias, os Estados, as sociedades, as civilizações. [...] a terceira parte, a história tradicional, necessária se pretendemos uma história não à dimensão do homem mas do indivíduo, uma história de acontecimentos [...] da agitação da superfície, [...] levantadas pelo poderoso movimento das marés, uma história com oscilações breves, rápidas nervosas.

Essas evoluções longas, apesar de encontrar na história das mentalidades um espaço fértil para seu desenvolvimento, o próprio Braudel chama atenção para sua aplicabilidade, de forma mais fácil, para a vida material, para o cotidiano das cidades, o capitalismo e sua dinâmica, entre outros aspectos (BRAUDEL, 1997).

Braudel enfatiza a continuidade, a permanência, a estrutura, a longa duração e não transformação e/ou mudança histórica. Deste modo, para a história são as permanências que darão sentido aos eventos. Segundo Reis, “A estrutura sofre o 'vento da história', que são seus eventos, e é obrigada a se rearticular, a mudar lentamente, a estrutura é o 'não há nada de novo', que envolve o evento, a novidade; ela é uma articulação dos 'elementos' já presentes nela" (REIS, 2007, p.104). De acordo com o próprio Braudel (1982, p.14),

[...] muito mais útil, é a palavra estrutura. Boa ou má, é ela que domina os problemas da longa duração. Os observadores do social entendem por 
estrutura uma organização, uma coerência, relações suficientemente fixas entre realidades e massas sociais. Para nós, historiadores, uma estrutura é, indubitavelmente, um agrupamento, uma arquitectura; mais ainda, uma realidade que o tempo demora imenso a desgastar e a transportar. Certas estruturas são dotadas de uma vida tão longa que se convertem em elementos estáveis de uma infinidade de gerações: obstruem a história, entorpecem-na e, portanto, determinam o seu decorrer. Outras, pelo contrário, desintegramse mais rapidamente. Mas todas elas constituem, ao mesmo tempo, apoios e obstáculos, apresentam-se como limites (envolventes, no sentido matemático) dos quais o homem e as suas experiências não se podem emancipar. Pense-se na dificuldade em romper certos marcos geográficos, certas realidades biológicas, certos limites da produtividade e até reacções espirituais: também os enquadramentos mentais representam prisões da longa duração.

Enquanto para Lévi-Strauss o tempo é entendido como algo "intemporal", em que a etnologia está preocupada com as sociedades sem histórias, ou seja, as sociedades "frias", de uma antropologia estruturalista que homogeneíza o tempo, por outro lado, a temporalidade braudeliana, mesmo com as prisões da longa duração e suas permanências, seu tempo é mais concretude e ação humana do que em Lévi-Strauss. Braudel está preocupado com uma história como ciência da perspectiva, de um tempo referente a "sociedades complexas ou quentes", o que já caracteriza o historiador como menos idealista e mais concretista, uma vez que sua ciência da perspectiva pode fornecer as dimensões das mudanças e transformações. Para Reis (2006, p.88),

Enquanto as ciências sociais tratam desses objetos sem a perspectiva temporal, os historiadores os põem em seu tempo longo [...] para se compreender uma "civilização", uma longa duração nas áreas geográfica, social, econômica, demográfica, cultural, mental, é preciso partir de casos concretos e chegar a "civilizações concretas".

Para Braudel (1982), a estrutura é a realidade desgastada pelo tempo, um tempo que se altera mesmo que de forma arrastada, em um devir pouco perceptível. Para isso, ele desenvolve a curta e média duração, constituindo apoios e obstáculos dos quais os homens e suas experiências não se podem emancipar. Uma realidade marcada pela geografia, biologia e produtividade, além do espírito e da mentalidade. O tempo é formado pelo espaço, entendido como algo dinâmico, um espaço de relações, concebido na rapidez e na multiplicidade. Desse modo, o tempo e espacialidade se confundem, ou melhor, o tempo se perde na espacialidade, em que o espaço é o depósito das vivencias históricas dos homens no mundo; o espaço freia o tempo. Para Poblet (2011, p.142-143),

Associando o conceito das temporalidades de Braudel ao sentido de lugar no campo do urbanismo, é possível pensá-lo como uma cristalização, sempre dinâmica e em processo, da combinação das temporalidades, longa, média e curta, sendo o lugar o resultado desse acúmulo das marcas físicas e 
simbólicas deixadas pelo tempo na forma da cidade e em suas relações e práticas sociais. Conforme o pensamento de Rossi (1998), o lugar é como um adensamento de uma diversidade de tempos e, também, de valores históricos que vão se acumulando. No desenvolvimento desta análise, emerge o lugar como um conceito-chave capaz de ser o elo entre as três temporalidades propostas por Braudel, visto que nele podem ser percebidos os efeitos de cada temporalidade, quer isoladamente ou em seu conjunto, dependendo do enfoque, do corte epistemológico que se propõe, ao observarmos uma dada realidade.

Neste sentido, a cidade para Braudel (1997, p.458) surge como o lócus da história, ao mesmo tempo em que ela faz, ela também é feita pela história, é uma entidade maior do que as vontades individuais dos homens. "Uma cidade cresce em determinado lugar, casa-se com ele e nunca mais o abandona, salvo raríssimas exceções”. Elas criam o capitalismo, são à base da economia-mundo e o lugar onde se desenrola a vida material, como é possível observar no último capítulo do primeiro volume da obra de Braudel Civilização Material, Economia e Capitalismo: Séculos XV-XVIII.

Tratar-se-ia sempre de destacar um espaço de grandes dimensões, associado à vida da cidade. $\mathrm{O}$ mesmo espaço, afinal, que se delimita conforme o raio de suas relações comerciais marcando aldeias, cidades, mercados que aceitem o seu sistema de medidas ou sua moeda, ou ambas as coisas, ou que, por vezes, falam seu próprio dialeto (BRAUDEL, 1997, p.449).

A dimensão do espaço e a geografia em Braudel permitem materialidade ao seu conceito de temporalidade - longa duração - uma vez que espaço e temporalidade são correlatos e a aplicabilidade dessa concretude se dá, sobretudo, na vida cotidiana, na produção da vida material, do capitalismo, dos próprios agentes históricos, apesar de Braudel diminuir o peso de uma ação histórica individual em função de uma ação que diz respeito a toda uma geração. Braudel compõe, conforme seu entendimento sobre o espaço, uma espécie de longa dimensão, algo que vai além do espaço da cidade em que atua como um sistema que ultrapassa os muros de seu espaço imediato e cria relações de dependência com outros lugares, cidades ou territórios dependentes dessa cidade, como suas extensões.

Todavia, Braudel (1997, p.513) pontua que todas as manifestações de povoamento denso partilham da tendência de "ficarem por aí por causa de uma força de inércia que é uma das grandes obreiras da história”. O autor entende uma civilização como estabelecimento remoto de agrupamentos humanos num determinado espaço, sendo, por isso, uma categoria histórica. A humanidade tende a unicidade após o fim do século XV. "Longa duração e civilização, estas ordens preferenciais chamam a si a classificação suplementar inerente às sociedades, também elas onipresentes". 
Braudel (1997, p.512) ainda informa que "[...] a vida material começa por se apresentar sob a forma episódica de milhares e milhares de faits divers". Na mesma página, Braudel afirma que são estas "séries" e "longas durações" que chamam sua atenção, pois indica uma ordem, equilíbrios e permanências, em que a "Uma 'lei', dizia Georges Lefebvre, "é uma constante"” com prazo longo ou médio, pois "A vida material submete-se mais facilmente a estas evoluções lentas do que os outros setores da história dos homens". Desse modo, o concreto e a vida material são fundamentais para Braudel, ao mesmo tempo em que o afasta do abstracionismo teórico de Lévi-Strauss. Pois,

O fato de esses problemas - o longo prazo, a civilização, a sociedade, a economia, o Estado, as hierarquias dos valores "sociais" - se imporem neste plano das realidades modestas da vida material basta, por si só, para provar que a história já aí se apresenta com seus enigmas, as suas dificuldades, as mesmas que todas as ciências humanas encontram quando às voltas com os seus objetos. $\mathrm{O}$ homem nunca se reduz a um personagem que se possa apreender numa simplificação aceitável. É o falso sonho de muita gente. Mal o agarramos no seu aspecto mais simples logo o homem se reafirma na sua complexidade habitual (BRAUDEL, 1997, p.513).

A universalidade, essa necessidade de explicar a totalidade em que a temporalidade não desfruta de uma dada espacialidade, onde sua geografia não é regional ou local, mas global.

Parece que o exemplo mais acessível continua a ser ainda o da reacção geográfica. O homem é prisioneiro, desde há séculos, dos climas, das vegetações, das populações animais, das culturas, de um equilíbrio lentamente construído de que não se pode separar nem correr o risco de voltar a pôr tudo em causa. Considere-se o lugar ocupado pela transumância na vida de montanha, a permanência em certos sectores da vida marítima, arreigados em pontos privilegiados das articulações litorais; repare-se na duradoura implantação das cidades, na persistência das rotas e dos tráficos, na surpreendente fixidez do marco geográfico das civilizações. As mesmas permanências ou sobrevivências dão-se no imenso campo do cultural (BRAUDEL, 1982, p.14-15).

Neste ponto, é possível observar a influência direta da geografia de Vidal de La Blache no pensamento braudeliano. Segundo Dosse (2003), Braudel retoma a herança de Vidal de La Blache e de seus axiomas, fruto dos anos em que foi aluno dos mestres da escola vidaliana. Isso faz com que o tempo e espaço, tanto em Braudel como em Vidal de La Blache sejam equivalentes. O espaço serve, desta forma, como fator explicativo dos múltiplos aspectos das civilizações. "O espaço, fonte de explicação, põe em causa ao mesmo tempo todas as realidades da história, todas as partes envolvidas da extensão: os Estados, as sociedades, as culturas, as economias" (BRAUDEL, 1998, p.12). E de acordo como é 
escolhido algum desses conjuntos, imediatamente se altera o significado e o papel do espaço, apesar de não ser de forma absoluta.

É neste sentido que Braudel (1998, p.35) afirma que de todas as abordagens do espaço, a econômica é a mais fácil de situar e de maior alcance, que além de ditar o ritmo do tempo material do mundo, todos os outros elementos que compõe a realidade do tecido social, interferem no seu funcionamento, do mesmo modo como são influenciadas. "A economia nunca está isolada, seu espaço são os mesmos onde se instalam e vivem outras entidades - a cultura, o social, a política - que incessantemente interferem nela para a favorecer, ou então para contrariar".

Dosse (2003, p.201) afirma que “[...] a temporalidade insere-se no espaço até desaparecer e ninguém se admira do fato de a história, nesse processo de naturalização, imobilizar-se no solo. A civilização até se define e algumas vezes se reduz ao espaço”. Desta forma, a geo-história seria uma civilização, uma instalação antiga de uma determinada humanidade em um determinado espaço que determina e fundamenta o alcance e, como continua Dosse (2003, p.201), “[...] não se deixa fechar no extrato da realidade humana, engloba tanto os fenômenos de ordem climática, quanto os fatos culturais", porque, como afirma o próprio o próprio Braudel “As mesmas permanências ou sobrevivências dão-se no imenso campo cultural" (BRAUDEL, 1982, p.15).

\section{A longa duração e sua dimensão "metafísica" enquanto representação temporal}

A geo-história se identifica com a longa temporalidade de uma a história, uma arquitetura de uma história encarcerada pelas permanências. Essa arquitetura permite a existência de condicionamentos nos quais homens e mulheres parecem permanecer como prisioneiros, em que o tempo degrada superficialmente, somente os contornos, jamais a estrutura das estruturas, a arquitetura.

A espacialidade da longa dimensão incorpora tudo e permite a concretização de uma história total. Percebemos através da geografia a valorização da longa duração e, ao mesmo tempo, a diminuição do homem como protagonista da história, que é substituído por um sujeito espacial. Encontra-se na longa dimensão o mecanismo para desacelerar a velocidade da história, insinuando a imobilidade, ou a própria inércia. A espacialização da temporalidade dissolve as forças contraditórias internas e a cisão concernente as mudanças, condicionam o homem e dita os contornos das permanências no seio das civilizações. 
A longa duração é uma arquitetura e atua como obstáculo, na medida em que também é suporte. Pois, para Braudel (1982, p.14) “O homem é prisioneiro, desde há séculos, dos climas, das vegetações, das populações animais, das culturas, de um equilíbrio lentamente construído de que não se pode separar nem correr o risco de voltar a pôr tudo em causa". Para Reis (2008, p.16), “Como obstáculo, ela se refere aos limites que os homens não podem ultrapassar: quadros geográficos, realidades biológicas, limites da produtividade, quadros mentais". Obstáculos que permitem uma leitura, ou melhor, interpretação de um certo inatismo e /ou a priorismo na longa duração braudeliana, permitindo entender certa ahistoricidade em sua concepção de tempo.

O historiador, para Braudel, articula evento e estrutura, ou seja, durações curtas, médias e longas. Seu tempo histórico não opõe evento e estrutura num sistema binário. De acordo com Reis (2008), Braudel articula o tempo curto a ciclos e interciclos de 10 a 60 anos e os tempos mais longos de 100 a 1000 anos. Braudel (1982, p.16) pontua que "Ciclos e interciclos e crises estruturais encobrem aqui as regularidades e as permanências de sistemas ou [...] de civilizações econômicas, isto é, de velhos hábitos de pensar ou agir, de marcos resistentes e tenazes $[\ldots]$ ".

Rodrigues (2009, p.167) destaca que "Sob o pano de fundo de um debate com LéviStrauss, o texto de Braudel recorre a uma concepção da temporalidade que, dotada das medidas de tempo e espaço e das escalas de duração reorienta para o coração da pesquisa historiográfica". Braudel se distancia em relação a Lévi-Strauss justamente em relação ao suposto movimento que dá a sua temporalidade, referentes a curta e média duração e, que mesmo as permanências oriundas da longa duração, ela aparentemente se move.

Braudel, nesse sentido, articula abstracionismo temporal com a concretude, quando diz que sua concepção de tempo encontra lugar privilegiado, não somente na história das mentalidades, mas também dentro do cotidiano dos homens e suas civilizações, nas cidades, no capitalismo, na economia, etc. Pois, "[...] de todas as abordagens do espaço, a econômica [...] é a mais fácil de situar e a de maior amplitude” (BRAUDEL, 1998, p.12), ou quando pontua que "A vida material submete-se mais facilmente a estas evoluções lentas do que os outros setores da história dos homens" (BRAUDEL, 1998, p.512) na qual dita o tempo material do mundo, na vida urbana cotidiana, na produção material do capitalismo e na dinâmica das cidades.

Dosse (2003, p.169) informa que Braudel inova em relação a Lévi-Strauss, quando toma emprestado seu discurso, "Ele lhe opõe o trunfo principal do historiador: a duração, não 
a da dupla tradicional acontecimento/datação, mas a longa duração que condiciona até as estruturas mais imutáveis que o antropólogo valoriza [...]"

Braudel (1982) parte da perspectiva da totalidade da história, colocada como resposta oriunda de uma infraestrutura em relação às camadas mais lentas da história., na qual todos os níveis e fragmentações do tempo da história, se compreendem a partir da profundidade e da semi-imobilidade e tudo que gravita em torno dela. Esta totalidade, ou melhor, universalidade pode ser identificada como uma característica da tradicional filosofia, como as filosofias da história, ou pelo menos uma de suas pretensões. O próprio Platão em seu esquema filosófico na relação Mundo das Ideias e Mundo Sensível, compartilha desta premissa universal, bem como Aristóteles e seu Motor Imóvel; Agostinho e a Cidade de Deus; Descartes com o Cogito; ou Kant e o sujeito transcendental, entre outros.

Da mesma forma é o que acontece com as filosofias da história em seu caráter linear, progressivo, da evolução das teorias das descontinuidades históricas e teleológico, o que contribui para percepções de mundo que modela a história, que observa (ou não) um sentido na trajetória do homem sobre a terra e qual é ele. É a interpretação da realidade do processo histórico fundamentada em concepções filosóficas. E aqui, a exemplo dos filósofos citados acima, poderíamos mencionar um panteon de estudiosos como: Giambatista Vico, o próprio Kant, Augusto Conte, Wilhem Dilthey, Benedetto Croce, Hegel, Karl Marx, dentre outros.

Tal universalidade está presente no seio do tempo histórico da longa duração, contribuindo para mais um indício de aportes teóricos que subsidiam um pensamento filosófico e/ou metafísico, como as referidas filosofias da história. Pois, esta universalidade pode ser entendida como um fator axiológico, permeada de regras, de leis e de imutabilidade que parece agora contaminar a história que tanto se esforçou para se distanciar das filosofias da história que a perseguiram durante o século XIX e início do XX.

Ainda podemos afirmar que o "casamento" entre a universalidade e as durações (longa, média e curta) também indicam possíveis apontamentos de que na temporalidade braudeliana, reside traços de aportes teóricos de uma filosofia historicista, pois tem a intenção de articular devir histórico com permanências (imobilidade), temas tradicionalmente ligados as formulações de filósofos, tão preocupados em explicar cosmogonias e cosmologias, basta atentarmos paras os antigos pensadores da Grécia Clássica, como Heráclito e Parmênides.

Assim, é possível relacionar a longa duração braudeliana como uma manifestação da imobilidade, conforme a geração de permanências e prisões que o tempo longo causa, na qual se torna sua estrutura para explicar os eventos das mudanças, mas sem modifica-las. Ou seja, mesmo existindo camadas de durações temporais, sendo a curta duração "responsável” para 
atentar as transformações na história de determinadas sociedades, estas transformações não atingem ou modificam a arquitetura do tempo longo. Desta maneira, não existe transformação de fato e mesmo existindo durações temporais, dando a impressão de movimento na história, ela não se move (imobilidade) quando se trata de transformar sua estrutura. Uma ahistoricidade que rege as durações no tempo histórico de Braudel.

A longa duração, também pode ser colocada como estrutural - por mais que Braudel prefira usar o termo arquitetura - e os outros tempos a sua volta, curta e média duração, interagem de maneira a confirmar o polo norteador, que é a do tempo longo. Conseguimos perceber que as permanências da longa duração, através de sua imobilidade passa a impressão de uma imutabilidade que proporciona a estagnação das mudanças, da não transformação e do o não movimento.

Observamos que mesmo que a temporalidade braudeliana seja tripartida, seja ela geográfica (longo), social (médio) ou individual (curto), estas permanecem conectadas a uma temporalidade global, universal e que as agrupam dentro de um mesmo conjunto. Portanto, o fato de existirem três temporalidades não significa que Braudel lhes atribuiu peso igual, uma vez que a longa duração ainda pode ser entendida como uma temporalidade causal, uma espécie de lei que produz precedentes e proporciona uma dinâmica que determina acontecimentos, mesmo sem estar sujeito às mesmas. Tudo isso dentro da totalidade, universalidade, como algo pré-estabelecido (axioma e/ou lei), inato, quase como um conceito a-histórico numa representação de tempo histórico. Conforme Dosse (2003, p. 174),

A sucessão das três temporalidades não significa que Fernand Braudel atribuía peso igual a cada uma. Há, incontestavelmente, uma temporalidade causal, fundadora da evolução dos homens e das coisas: a longa duração; e como se refere a natureza, é esta que desempenha, em última instância, o papel determinante. Encontra-se, então, um discurso histórico no limite entre natureza e cultura.

Para o mesmo autor, Braudel transfere o factual para a ordem da superficialidade, da aparência, para conseguir deslocar o olhar do historiador para o tempo longo, as evoluções longas e as permanências. Neste contexto, a longa duração adquire lugar privilegiado, pois determinará o conjuntural e o factual e as fronteiras do possível e do impossível, ao ajustar as variáveis a um determinado patamar. Deste modo, as estruturas da longa duração pertencem à esfera do irreversível, já que o acontecimento pertence à margem e a conjuntura segue um movimento cíclico.

Ou seja, Braudel quando trata da longa duração, sempre afirmou que esta gerava permanências, isto é, a quase imutabilidade, a quase inércia, a mudança lenta, quase 
imperceptível. Nota-se que o termo "quase" é continuamente empregado, o que dá a entender que Braudel não quer de imediato assumir a total imobilidade. Contudo, outra impressão é deixada por Braudel, é quando ele diz que a curta e média duração são responsáveis pelas mudanças, mas apenas aquelas mudanças que só arranha a estrutura - longa duração - e que não é capaz de alterá-la. Neste contexto, podemos assumir que o "quase" que Braudel utiliza em sua obra pode ser assimilada ao tempo curto e médio e o termo da "imobilidade", a longa duração. Então se a curta e média duração (leia-se o termo "quase") são apenas as responsáveis por um devir incapaz de provocar alguma ruptura na estrutura (longa duração), isso quer dizer que quando Braudel diz quase imobilidade, quase inércia ou permanências, parece lícito entender, automaticamente, a imobilidade de fato, a inércia e todos os outros termos sinônimos. Na prática, é imóvel, mas no discurso diz-se quase imóvel.

Dosse (2003, p.175) interpreta que "Essa temporalidade de fôlego longo oferece a vantagem de poder ser decomposta em séries de fenômenos que se repetem, em séries de permanências que deixam aparecer os equilíbrios e a ordem geral subjacente à desordem aparente do mundo factual". Ou seja, Braudel, através de seu tempo histórico, neste contexto, não conseguiu escapar das armadilhas de uma filosofia do e no historicismo, sobretudo em sua representação temporal.

Também concordamos com a assertiva de Dosse (2003) quando afirma que o homem se torna prisioneiro desta temporalidade longa e nada pode fazer enquanto a isso, pois a sua liberdade é ínfima e está sujeito às contingências do meio natural, hábitos, gestos inconscientes, etc. $\mathrm{O}$ homem perde sua historicidade, sendo engolido por ela, da mesma maneira que a sofre. $\mathrm{O}$ homem é um mero espectador e objeto de sua própria temporalidade. "Há, mais lenta ainda que a história dos homens nas suas civilizações, quase imóvel, uma história dos homens nas suas relações concisas com a terra que os sustenta e os alimenta". (DOSSE apud BRAUDEL, 20003, 175).

\section{Considerações finais}

Braudel é um personagem fundamental, uma figura exponencial para a manutenção dos preceitos da Escola dos Annales da primeira geração e na renovação dos métodos historiográficos, notadamente pela sua elaboração temporal sobre a longa duração. O seu tempo longo subsidia teoricamente, não só os temas relativos à história das mentalidades, como também se refere à formação do capitalismo, do mundo material, do cotidiano, entre outros. 
Ao abordar as categorias de espaço e tempo em Braudel, ressalta-se a importância de sua formulação de representação de tempo, na medida em que sua perspectiva de mundo traz para a contemporaneidade elementos singulares para ao conhecimento da formação das sociedades. Quando o espaço é colocado como fundamental na constituição da abordagem histórica aloca a história em uma espécie de ciência da diversidade, de acordo com a relação estabelecida entre tempo e espaço.

A temporalidade de Braudel se apresenta como resposta as investidas do estruturalismo antropológico de Lévi-Strauss, que além de atacar a história, seja enquanto área de conhecimento ou ciência, também toma do historiador e da história lugar privilegiado referente à sociedade e as instituições de ensino e conhecimento nas áreas de ciências humanas e sociais. Braudel funda uma nova forma de pensar o homem e a civilização através de sua formulação de representação do tempo.

Por fim, a partir de uma discussão epistemológica e metodológica em torno do conhecimento da história e de sua "fuga" dos conceitos totalizantes da filosofia, como a filosofia da história, é que alguns questionamentos nortearam este artigo em relação ao tempo histórico de Braudel, como: se a longa duração não seria uma aproximação, ou melhor, um esboço com as formulações totalizantes de uma filosofia da história aos moldes tradicionais? Teria mesmo a escola dos Annales, fundamentalmente a segunda geração, que tem em Braudel seu principal expoente, conseguido deixar de lado a influência de uma certa metafísica - termo tão íntimo da filosofia tradicional - ao se aproximarem das ciências sociais? O Conceito de longa duração braudeliano, deste modo, também não pode ser interpretado como a-histórico e/ou atemporal, ao apresentar certa imobilidade produzida por suas permanências de longa duração? A longa duração é de fato uma ruptura com a influência da filosofia na história, como as filosofias da história, como era nos séculos XVIII e XIX, ou é apenas mais uma roupagem contemporânea e/ou uma continuação desta influência da filosofia no seio da história? A utilização da geo-história, isto é, da longa dimensão que é resultante da concepção de história por parte de Braudel, que incorpora a geografia para dissolver temporalidade e espaço, para se alcançar uma totalidade na sua dimensão, não seria outro elemento que constitui as preocupações dos filósofos tradicionais como a universalidade e/ou totalidade de uma concepção globalizante da história?

\section{Referências Bibliográficas}

BRAUDEL, Fernand. A Longa Duração. In: Escritos sobre a História. São Paulo: Perspectiva, 1978. 
1998.

Civilização Material, Economia e Capitalismo. 3 vols. São Paulo: Martins Fontes, História e Ciências Sociais. Lisboa: Editorial Presença, 1982.

O Mediterrâneo e o mundo mediterrânico na época de Filipe II. 2 vols. Lisboa: Publicações Dom Quixote, 1983.

CARDOSO, Ciro Flamarion; VAINFAS, Ronaldo. Domínios da História: Ensaio de Teioria e Metodologia. Rio de Janeiro: Campus, 1997.

DOSSE, François. A História em Migalhas: dos Annales à Nova História. Campinas: Unicamp, 2003.

GARDINER, Patrick. Teorias da História. Lisboa: Fundação Calouste Gulbenkian, 2004.

HARTOG, François. O Olhar distanciado: Lévi-Strauss e a História. Revista Topoi. n. 12, v. 7. Rio de Janeiro, UFRJ, 2006, p. 9-24.

. Regimes de Historicidade. Presentismo e Experiências do Tempo. Belo Horizonte:

Editora Autêntica, 2013.

LÉVI-STRAUSS, Claude. História e Etnologia. In: Antropologia Estrutural. São Paulo: Cosas \& Naify, 2008.

História e etnologia. In: Antropologia estrutural. Trad. Chaim Katz e Eginardo Pires. 6.ed. Rio de Janeiro: Tempo brasileiro, 2003.

. Antropologia estrutural, Rio de Janeiro: Tempo Brasileiro, 1975.

POBLET, Maria Del Mar. A Dimensão Espaço-Temporal em Fernand Braudel: Aportes Teóricos para a Geografia. Belo Horizonte, UFMG, 2001.

REIS, José Carlos. Escola dos Annales: A Inovação em História. São Paulo: Paz e Terra, 2000 .

. História da História (1950/60) História e Estruturalismo: Braudel versus Lévi-

Strauss. História e Historiografia. n.1, Rio de Janeiro, UniRio, p. 8-18.

História, entre a Filosofia e a Ciência. Belo Horizonte: Autentica, 2006.

História e Teoria: Historicismo, Modernidade, Temporalidade e Verdade. Rio de Janeiro: FGV, 2006.

Nouvelle Histoire e tempo histórico: a contribuição de Febvre, Bloch e Braudel.

São Paulo: Ática, 1994.

RODRIGUES, José Estrada. Lévi-Strauss, Braudel e o tempo dos historiadores. Revista Brasileira de História. n. 57, v.29São Paulo, 2009, p. 165-186. 